\title{
Métodos de diagnóstico para la detección de la infección por Helicobacter pylori
}

\author{
Javier Chahuán A. ${ }^{\text {, }}$ Margarita Pizarro R. ${ }^{1}$, Luis A. Díaz P. ${ }^{1}$, \\ Alejandro Villalón $F^{3}$ y Arnoldo Riquelme P.,
}

1Departamento de Gastroenterología Facultad de Medicina Pontificia Universidad

Católica de Chile.

Santiago, Chile.

2Departamento de

Ciencias de la Salud

Facultad de Medicina

Pontificia Universidad

Católica de Chile.

Santiago, Chile.

${ }^{3}$ Residente

Departamento de

Gastroenterología,

Facultad de Medicina,

Pontificia Universidad

Católica de Chile.

Santiago, Chile.

Recibido: 16 de junio de 2020

Aceptado: 11 de julio de 2020

Correspondencia a: Dr. Arnoldo Riquelme Profesor Titular

Departamento de

Gastroenterología

Facultad de Medicina

Pontificia Universidad

Católica de Chile.

Santiago, Chile.

a.riquelme.perez@

gmail.com

\section{Diagnostic methods for detection of Helicobacter pylori infection}

Helicobacter pylori (H. pylori) is a Gram-negative bacterium that survives in gastric acidity. Approximately $50 \%$ of the world population is a carrier of this infection and the prevalence is higher in African and Latin American populations. The clinical manifestations associated with this infection are gastritis, peptic ulcers, MALT lymphoma, gastric cancer (GC), and other extra-digestive pathologies. Chronic $H$. pylori infection is the most important risk factor for GC development. There are several diagnostic methods to detect $H$. pylori infection. The most widely used invasive methods are the rapid urease test and Giemsa staining in gastric biopsies. Culture and molecular techniques are very useful for the study of $H$. pylori presence and antibiotic resistance, but they are not easily available in health centers. The most widely used non-invasive methods are the urea breath test and bacterial antigens in stools. Serological studies are used for population studies. The use and indication of the diagnostic method for detecting H. pylori infection will depend on the clinical manifestations, risk factors for GC, and the age of the patient.

Key words: Helicobacter pylori, diagnosis, diagnostic tests, gastroduodenal ulcers, gastric cancer.

\section{Resumen}

Helicobacter pylori (H. pylori) es una bacteria Gram negativa que sobrevive a la acidez gástrica. Se estima que aproximadamente el $50 \%$ de la población mundial es portadora de esta infección, siendo mayor la prevalencia en poblaciones africanas y latinoamericanas. Entre las manifestaciones clínicas asociadas a esta infección se encuentra gastritis, úlceras pépticas, linfoma MALT, cáncer gástrico y otras patologías extradigestivas. La infección crónica por $H$. pylori es el factor de riesgo más importante para el desarrollo de CG. Existen diversos métodos diagnósticos para detectar la infección por $H$. pylori, los métodos invasivos más utilizados son la prueba rápida de ureasa y tinción de Giemsa en biopsias gástricas. El cultivo y las técnicas moleculares son de gran utilidad para el estudio de presencia de $H$. pylori y estudios de resistencia antibiótica, pero suelen estar poco disponibles en los centros de atención en salud. Los métodos no invasivos más utilizados son la prueba de aire espirado con urea marcada y antígeno bacteriano en deposiciones. Los estudios serológicos son utilizados para estudios poblacionales. El uso e indicación de cada uno de los métodos de diagnóstico para la detección de infección por $H$. pylori, dependerá de las manifestaciones clínicas, los factores de riesgo de CG y la edad del paciente.

Palabras clave: Helicobacter pylori, diagnóstico, pruebas diagnósticas, úlcera péptica, cáncer gástrico.

\section{Introducción}

Helicobacter pylori (H. pylori) ha convivido con la humanidad desde hace miles de años. Estudios de migración sugieren que la bacteria se diseminó desde África, con los humanos, hace 60.000 años ${ }^{1}$. En 1983 Robin Warren y Barry Marshall describieron el papel etiológico de esta bacteria en la gastritis y úlcera péptica $^{2}$, recibiendo el premio Nobel de Medicina el año 2005. El uso de antibióticos redujo de manera radical la recurrencia de úlceras gástricas y duodenales, así como la necesidad de su resolución quirúrgica y las respectivas complicaciones ${ }^{3}$. La Organización Mundial de la Salud clasificó la infección crónica por H. pylori como un carcinógeno tipo I en $1994^{4}$ y la reconfirmó en $2009^{5}$.

H. pylori infecta a aproximadamente la mitad de la población mundial ${ }^{6}$. Su prevalencia varía de acuerdo con la geografía, demografía, raza/etnia, y factores socioeconómicos, siendo más alta en países en vías 


\section{Medicina Basada en la evidencia en Gastroenterología}

de desarrollo ${ }^{6-8}$. Adicionalmente, dentro de un mismo país, se observan diferencias en la prevalencia9. En la Figura 1 se presenta una estimación de la prevalencia de infección por $H$. pylori en distintas regiones del mundo, con cifras de $70 \%$ o más en países de Latinoamérica y África. Chile es considerado como un país de alta prevalencia de infección por $H$. pylori, con cifras de hasta $3 / 4$ de la población en algunos estudios ${ }^{10,11}$.

H. pylori es una bacteria Gram negativa, espiroidea y flagelada, capaz de sobrevivir a la acidez gástrica a través de la acción de la ureasa ${ }^{13}$. Esta enzima convierte la urea, presente en el lumen gástrico, en dióxido de carbono y amoníaco, lo que alcaliniza el medio alrededor de la bacteria. Una vez en el lumen gástrico, la bacteria se mueve a través de la capa de mucus, y alcanza la superficie apical de las células del epitelio gástrico ${ }^{13}$. Todos los individuos infectados por H. pylori desarrollan gastritis, ya sea una pangastritis o una gastritis de predominio antral ${ }^{14}$, siendo una infección fundamentalmente asintomática ${ }^{15}$. Sin embargo, en algunos individuos se asocia a distintas patologías gastrointestinales. Alrededor de 1-10\% de los pacientes infectados por H. pylori desarrollan úlcera péptica (gástrica o duodenal) ${ }^{16}$. Los pacientes con úlceras gástricas se caracterizan por una reducción de secreción ácida gástrica, una pangastritis predominante del cuerpo gástrico y una probabilidad mayor de progresión hacia gastritis atrófica ${ }^{17}$. En contraste, en los pacientes con úlceras duodenales, la infección por H. pylori provoca inflamación de la mucosa gástrica antral y aumento de secreción de gastrina ${ }^{18}$. La infección por $H$. pylori contribuye a la carcinogénesis gástrica, produciendo una inflamación persistente y cambios moleculares (genéticos y epigenéticos), que contribuyen a inestabilidad del epitelio. El riesgo de CG está influido tanto por factores del huésped como de virulencia bacterianos, entre los que principalmente se incluye CagA y VacA ${ }^{17,19}$. La infección por $H$. pylori se relaciona, además, con el desarrollo del linfoma de MALT (tejido linfoide asociado a mucosas, mucosa associated lymphoid tissue, en inglés) y se presenta en $<0,01 \%$ de los pacientes infectados. En la mayoría de los pacientes, la erradicación del H. pylori produce la curación de la enfermedad sin necesidad de otro tipo de tratamiento ${ }^{20}$. La infección por $H$. pylori también se ha relacionado en algunos casos con patologías extradigestivas, entre las que se encuentran las siguientes:

- Anemia ferropriva no explicada, donde un metaanálisis realizado por Hudak y colaboradores ${ }^{21}$ mostró que los individuos infectados por $H$. pylori tienen mayor probabilidad de padecer anemia por deficiencia de hierro, en comparación con aquellos no infectados.

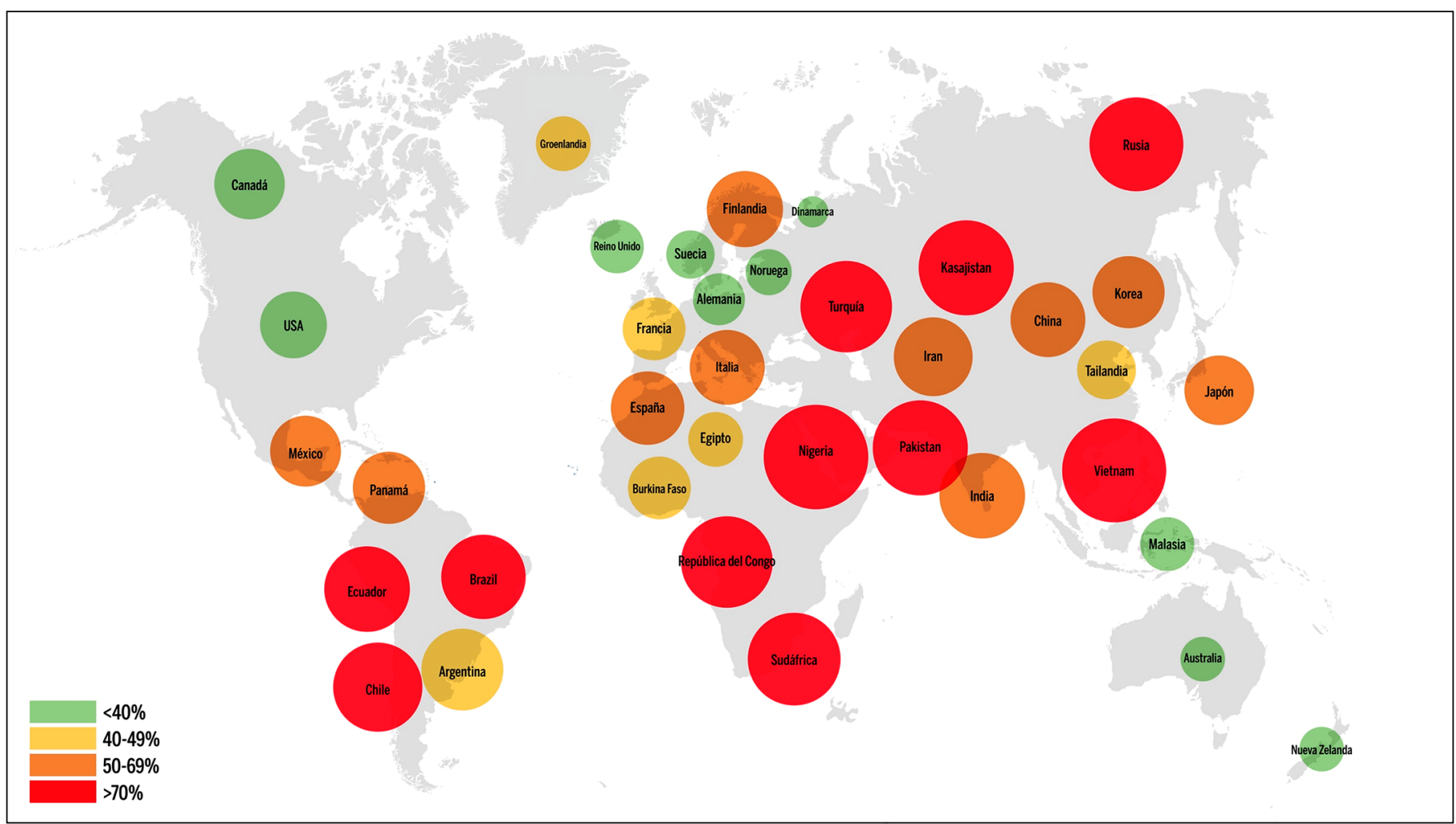

Figura 1. Prevalencia de infección por H. pylori (Adaptado de: 6, 12). 


\section{Medicina Basada en la evidencia en Gastroenterología}

- Púrpura trombocitopénico idiopático (PTI): donde la erradicación de la bacteria se relaciona con un incremento del conteo plaquetario en más de $50 \%$ de los pacientes ${ }^{22}$.

- Deficiencia de vitamina $\mathrm{B}_{12 \text { : }}$ la infección por $H$. pylori puede causar malabsorción de algunos micronutrientes entre los que se encuentra la vitamina $\mathrm{B}_{12}$. El tratamiento de la infección se asocia a un incremento de los niveles de esta vitamina ${ }^{23}$.

- Otros estudios sugieren que la infección por $H$. pylori se relaciona con patologías neurológicas, cardiovasculares, endocrinológicas, y dermatológicas, pero se requiere mayor evidencia para aceptar o refutar estas asociaciones ${ }^{24}$.

El mecanismo exacto de transmisión de H. pylori no es conocido. La vía de contagio más aceptada es de persona a persona, a través de contacto oraloral, fecal-oral o ambas, probablemente durante la infancia, influyendo el bajo nivel socioeconómico, las condiciones de hacinamiento, la existencia de un familiar portador de $H$. pylori y el consumo de agua no potable ${ }^{25}$.

Las indicaciones de tratamiento de erradicación son diversas, y la terapia estándar de primera línea en Chile combina un inhibidor de la bomba de protones con amoxicilina y claritromicina. Existe una crecien- te resistencia antimicrobiana en $H$. pylori, lo que ha motivado el desarrollo de esquemas alternativos de cuadriterapia, como aquellos que incluyen bismuto ${ }^{26}$. Dada la heterogeneidad poblacional en la prevalencia de infección por $H$. pylori, manifestaciones clínicas y resistencia antimicrobiana, se recomienda que la toma de decisiones, clínicas y de salud pública, se basen en evidencia local.

\section{Diagnóstico de la infección por $\boldsymbol{H}$. pylori}

Para el diagnóstico se cuenta con múltiples métodos, tanto invasivos como no invasivos. No existe un gold standard bien definido, siendo muchas veces considerada la combinación de métodos diagnóstico como el gold standard ${ }^{27}$. En ese contexto, al evaluar la sensibilidad y especificidad de los distintos métodos diagnósticos, se debe considerar cuál es el gold standard utilizado (Tabla 1).

\section{Métodos invasivos}

\section{Prueba rápida de ureasa (PRU)}

Es una prueba indirecta de la presencia de $H$. pylori en la mucosa gástrica. Solo detecta infección

Tabla 1. Comparación de los distintos métodos diagnósticos

\begin{tabular}{|c|c|c|c|}
\hline Prueba & Sensibilidad (\%) & Especificidad (\%) & Uso \\
\hline $\begin{array}{l}\text { Prueba rápida de } \\
\text { ureasa }\end{array}$ & $80-95^{28,45,46}$ & $97-99^{28,45,46}$ & $\begin{array}{l}\text { Requiere de biopsia gástrica. Rápido. Puede tener falsos negativos } \\
\text { en contexto de uso de IBP, antibióticos, bismuto o hemorragia } \\
\text { digestiva } \\
\text { Permite erradicar rápidamente } \\
\text { No se recomienda para evaluar la erradicación }\end{array}$ \\
\hline Histología & $\begin{array}{l}90^{47} \\
\text { Uso de IHQ aumentaría } \\
\text { sensibilidad } \\
>95^{42}\end{array}$ & $\begin{array}{l}97^{47} \\
>95^{42}\end{array}$ & $\begin{array}{l}\text { Biopsias protocolizadas permiten evaluar la gastritis y presencia } \\
\text { de } H \text {. pylori. Disminuye con uso de IBP. Múltiples tinciones. Se } \\
\text { puede agregar inmunohistoquímica en casos puntuales }\end{array}$ \\
\hline Cultivo & Variable $60^{41}$ & $98-100^{41,48}$ & $\begin{array}{l}\text { Laborioso, caro y poco disponible en nuestro medio. Permitiría } \\
\text { evaluar susceptibilidad antibiótica }\end{array}$ \\
\hline PCR & $97-100^{35,36}$ & $98^{36}$ & $\begin{array}{l}\text { Permite identificar genes específicos de la bacteria y además eva- } \\
\text { luar susceptibilidad antibiótica. Algunos consideran que podría } \\
\text { ser el gold standard }\end{array}$ \\
\hline Prueba serológica & $55,6-100^{37}$ & $58,7-96,8^{37}$ & $\begin{array}{l}\text { Varía según el kit usado. No detecta solo infección activa. No } \\
\text { puede usarse para monitorización de erradicación }\end{array}$ \\
\hline $\begin{array}{l}\text { Antígeno en } \\
\text { deposiciones } \\
\text { H. pylori }\end{array}$ & $83^{39}$ & $87-94^{38}$ & $\begin{array}{l}\text { Existen pruebas que usan inmunoensayos enzimáticos y otros } \\
\text { inmunocromatográficos. Fácil de implementar. Se puede usar pre/ } \\
\text { post tratamiento }\end{array}$ \\
\hline
\end{tabular}

IHQ inmunohistoquímica; IBP inhibidores de bomba de protones. 
activa, a diferencia de la serología. La prueba requiere una biopsia gástrica, que se añade a un dispositivo, donde la muestra se une a urea y luego se detectan los productos de la hidrólisis de urea, amonio o dióxido de carbono, dada la presencia de la enzima ureasa, en la bacteria ${ }^{28}$ (Figura $\left.2 \mathrm{~A}\right)$. Una PRU $(+)$ requiere alrededor de $10^{5} \mathrm{H}$. pylori en la muestra ${ }^{28}$. La velocidad de la reacción de la PRU depende de la carga bacteriana y la temperatura. Existen falsos negativos, en contexto de uso de inhibidores de bomba de protones, bismuto, antibióticos o la presencia de metaplasia intestinal ${ }^{28}$. Los falsos positivos son raros y ocurren cuando hay presencia de otros microorganismos productores de ureasa ${ }^{29}$ los que, con baja probabilidad, se encontrarán presentes en concentración suficiente para producir un resultado positivo. La PRU no se recomienda para chequear la erradicación, salvo que haya indicación de endoscopia digestiva ${ }^{14}$.

\section{Histología}

En muchos estudios se considera esta técnica como el gold standard. Para la histología se deben tomar muestras de biopsia gástrica, las que serán evaluadas por un patólogo. Existen diferentes tinciones para la búsqueda de $H$. pylori dentro de las que encontramos hematoxilina-eosina, además de otras como Genta, Warthin-Starry de plata y Giemsa. La tinción de Giemsa modificada sería la primera opción, por ser más barata y reproducible con buenos resultados, además, podría tener más especificidad que la tinción con hematoxilina-eosina ${ }^{30,31}$. Se podría considerar añadir inmunohistoquímica a casos con gastritis crónica, gastritis atrófica y metaplasia intestinal, o en seguimiento de biopsias luego de erradicación ${ }^{14}$. Respecto a las muestras, el protocolo de Sydney modificado ${ }^{32}$, el cual se usa como estándar para reportar la gastritis de forma universal, incluye 5 biopsias: 2 de antro, 1 de ángulo y 2 de cuerpo gástrico y tiene la ventaja de identificar $H$. pylori en individuos con gastritis crónica con más de 15-20 años de evolución, con cambios atróficos del antro y consecuente reducción de la población de $H$. pylori en ese sitio $^{33}$. La ventaja de la histología es que, además de informar sobre la presencia de $H$. pylori, permite evaluar el grado de inflamación. La sensibilidad puede disminuir en pacientes que usan inhibidores de bomba de protones (IBP) y hay que tener precaución en pacientes que usan anticoagulantes o con patologías crónicas, que aumentan el riesgo de sangrado post biopsia ${ }^{31}$. Otra desventaja es que el diagnóstico no es inmediato y es operador dependiente ${ }^{34}$.

\section{Cultivo}

H. pylori puede ser cultivado desde biopsias gástricas, pero este microorganismo requiere un ambiente microaerofílico y un medio complejo. El aislamiento de la bacteria es variable, por su dificultad de cultivar, recuperándose el microorganismo de entre $50-70 \%$ de los pacientes infectados ${ }^{27}$. El valor del cultivo es que permite estudiar susceptibilidad antibiótica, lo que facilita guiar el tratamiento, especialmente en pacientes que fallan a la primera línea ${ }^{14}$.

\section{Pruebas moleculares}

Las pruebas moleculares pueden ser útiles en el diagnóstico de infección por $H$. pylori. La más utilizada es la reacción en cadena de la polimerasa o PCR, la cual permite, además de la detección de bacterias, evaluar genes patógenos y específicos para la resistencia a antimicrobianos. Para el uso de la PCR, se utilizan genes conservados en la bacteria, tales como ureA, ureC, 16SrRNA, 23SrRNA y Hsp6027. Otra ventaja de este método es que se puede extraer la muestra de la biopsia utilizada para la PRU ${ }^{35}$. Algunos estudios han mostrado sensibilidad para este método de diagnóstico de $H$. pylori hasta $100 \%$ y especificidad $98 \%{ }^{36}$ y algunos autores han planteado que podría ser considerado como el gold standard, al usar partidores específicos para genes conservados de la bacteria ${ }^{27}$. Su uso se podría considerar en pacientes que acuden a endoscopia digestiva alta bajo condiciones supresoras como uso de inhibidores de bomba de protones o uso reciente de antibióticos y en pacientes con fracaso a esquema de primera o segunda línea empírica, ya que cumple con el propósito de establecer la presencia de $H$. pylori y estudiar la resistencia antibiótica por técnicas moleculares.

\section{Métodos no invasivos}

\section{Serología}

La serología por $H$. pylori muestra exposición al microorganismo, tiene sensibilidad y especificidad variable según el kit serológico usado ${ }^{37}$. Una limitación de los estudios serológicos es que no detectan infección activa, por lo que no puede usarse para monitorizar la terapia ${ }^{14}$. Su uso es de mayor utilidad en estudios poblacionales de prevalencia de infección por H. pylori.

\section{Antígeno en deposiciones de $\mathrm{H}$. pylori}

Dentro de estos métodos de detección, existen pruebas que usan la técnica del inmunoensayo enzimático y otros que son ensayos inmunocromatográficos rápidos. Algunos utilizan anticuerpos monoclonales y otros anticuerpos policlonales específicos para antígenos de $H$. pylori $^{38}$. Un estudio turco mostró que, en pacientes dispépticos, considerando la histología y la PRU (+) como diagnóstico de la enfermedad, al analizar 5 antígenos en deposiciones distintos, se obtiene una sensibilidad entre $48,9 \%-92,2 \%$ y especifi- 


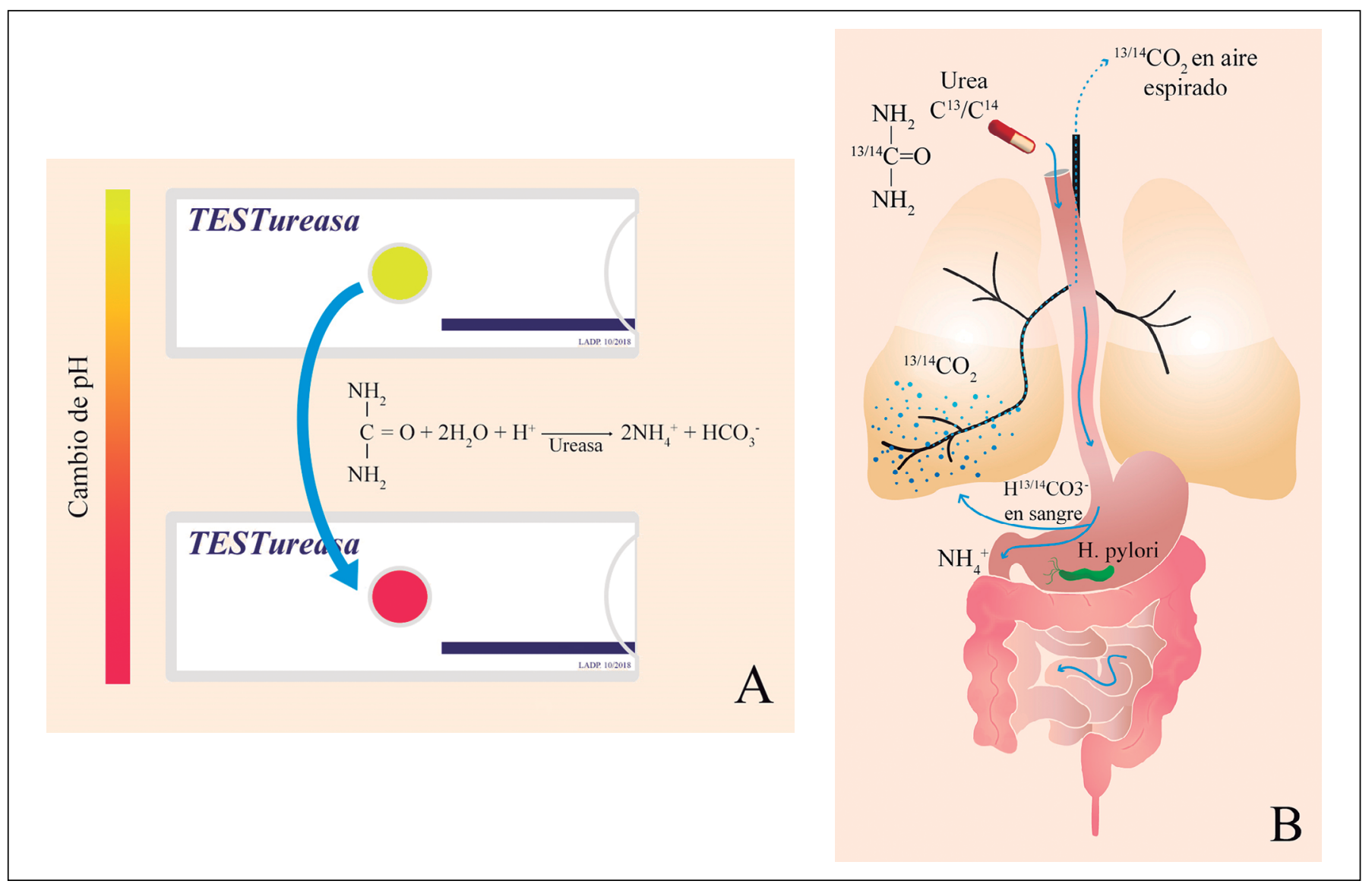

Figura 2. Principios del funcionamiento de las pruebas de ureasa $(\mathbf{A})$ y aire espirado con urea marcada con ${ }^{13} \mathrm{C} 0{ }^{14} \mathrm{C}(\mathbf{B})^{12}$.

cidad entre $87 \%-94,4 \%{ }^{38}$. Una revisión Cochrane, que comparó de manera indirecta métodos no invasivos, considerando 29 estudios que incluían antígeno en deposiciones (2988 pacientes), con una especificidad fija de $90 \%$ e histología como gold standard, encontró una sensibilidad de $83 \%{ }^{39}$. La ventaja de esta prueba es que es fácil de implementar en distintos centros, y la muestra puede ser tomada en domicilio. Además, el antígeno en deposiciones ha sido evaluado en el control de erradicación de $H$. pylori, presentando buen rendimiento diagnóstico ${ }^{40}$. Se debe tener precaución en pacientes con diarrea, lo que podría disminuir la sensibilidad de la prueba por la dilución de éste ${ }^{41}$. En el consenso de Maastritch V/Florence se considera el antígeno en deposiciones como alternativa para el diagnóstico de erradicación post tratamiento de $H$. pylori ${ }^{14}$.

\section{Prueba de aire espirado}

Para esta prueba se utiliza la ingestión de urea marcada con ${ }^{13} \mathrm{C} \mathrm{o}{ }^{14} \mathrm{C}$. Si el H. pylori está presente, la enzima ureasa de la bacteria libera el $\mathrm{CO}_{2}$ marcado con el isótopo, lo que es medido y comparado con un valor basal ${ }^{42}$. La sensibilidad y especificidad en general es mayor de $90 \%{ }^{43}$. $\mathrm{El}^{14} \mathrm{C}$ es menos utilizado por ser un isótopo radioactivo que limita su uso en mujeres embarazadas y niños, aunque la dosis de radiación es baja (1microCi) ${ }^{44}$ (Figura $2 \mathrm{~B}$ ). Se deben suspender los IBP previo al examen porque disminuye su sensibilidad ${ }^{14}$. La ventaja de la prueba de aire espirada es que no es invasiva, y puede ser usada además, para evaluar la erradicación de $H$. pylori, con un gran rendimiento diagnóstico ${ }^{40}$. Es el método de erradicación sugerido en primer lugar en consenso de Maastritch V/Florence ${ }^{14}$.

\section{Métodos diagnósticos y uso de inhibidores de bomba de protones}

Los inhibidores de la bomba de protones (IBP) son fármacos muy usados para aliviar los síntomas de la enfermedad por reflujo gastroesofágico $(\mathrm{ERGE})^{49}$. El uso de ellos interfiere con la sensibilidad de exámenes 
diagnósticos para la determinación de infección por H. pylori. Los IBP incrementan el pH gástrico modificando la densidad y distribución del H. pylori, lo que pueda llevar a falsos negativos, siendo recomendado por guías suspenderlo al menos 2 semanas previo a testear infección por H. pylori ${ }^{14}$.

\section{Estrategia racional del uso de diferentes métodos de diagnóstico de infección por $\boldsymbol{H}$. pylori}

Dependiendo del contexto clínico del paciente, las manifestaciones clínicas, y la prevalencia de infección por H. pylori y de CG a nivel poblacional, la aproximación diagnóstica puede diferir. En caso de tratarse de un paciente con dispepsia, sin síntomas de alarma, sin antecedentes familiares de primer grado de CG y menor de 40 años, la recomendación es de "testear y tratar" con un método no invasivo como prueba de aire espirado o antígeno en deposiciones de $H$. pylori. Esta estrategia es costo-efectiva, en la prevención de úlcera péptica y a largo plazo, reduciendo el riesgo de CG, incluso en países con bajo riesgo de CG como España $^{50}$.

Un artículo recientemente publicado, demostró que la erradicación de $H$. pylori en familiares de primer grado de pacientes con $\mathrm{CG}$ disminuye la aparición de esta patología en $55 \%$ con respecto a aquellos no erradicados (seguimiento promedio 9,2 años) ${ }^{51}$. Otros estudios también han mostrado que el tratamiento de erradicación de $H$. pylori es más efectivo en prevenir el CG si el tratamiento es prescrito previo al desarrollo de lesiones preneoplásicas ${ }^{52}$.

Por lo tanto, la estrategia de uso de los métodos invasivos o no invasivos dependerá de los factores de riesgo de CG que tenga cada paciente. Se consideran factores de riesgo: baja de peso, disfagia, hemorragia digestiva, vómitos o antecedente de $\mathrm{CG}$ en familiar de primer grado. Se sugiere un tamizaje selectivo en la población, con el fin de priorizar la búsqueda de pacientes con mayor riesgo de cáncer, sin aumentar de forma desproporcionada los recursos del sistema de salud ${ }^{53}$ (Figura 3). A modo de ejemplo, se señalan algunos escenarios clínicos en la Tabla 2 con los métodos diagnósticos sugeridos.

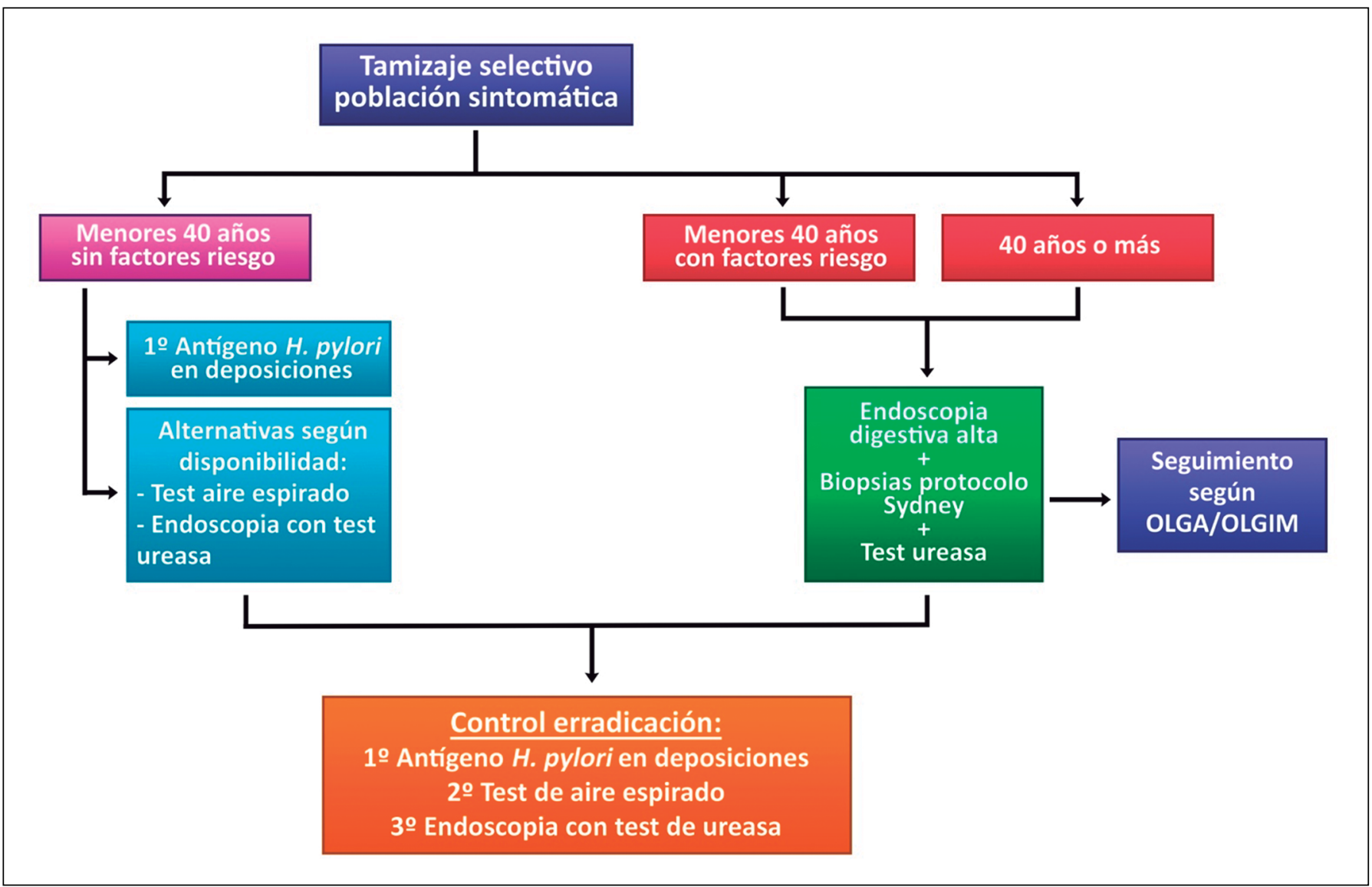

Figura 3. Tamizaje selectivo de población sintomática según edad y factores de riesgo ${ }^{53}$. 


\section{Medicina Basada en la evidencia en Gastroenterología}

Tabla 2. Escenarios clínicos y pruebas diagnósticas de $\boldsymbol{H}$. pylori a considerar (para dicho escenario)

\section{Escenario clínico}

Paciente que acude de forma electiva a una unidad de endoscopia para estudio con endoscopia digestiva alta

- Estudio en pacientes mayores de 40 años con síntomas digestivos

- En pacientes con biopsia gástrica por Protocolo de Sydney previamente realizada y que pese a antecedente familiar de primer grado con CG o control de úlceras gástricas, ya tiene etapificación histológica

- Pacientes con indicación de estudio biopsias por Protocolo Sydney

- Control de erradicación de úlceras gástricas en pacientes que requieren biopsia

- Pacientes con sospecha de CG

- Estudios de susceptibilidad bacteriana (poblacionales)

- Estudios de investigación

Pacientes sin riesgo elevado de CG que:

- Consulte por dispepsia ( $<40$ años)

- Requiera control de erradicación H. pylori

- Pacientes con fracaso a la erradicación H. pylori en esquema de segunda línea

- Paciente con condiciones clínicas que disminuyan la sensibilidad de otras técnicas diagnósticas (hemorragia digestiva alta, uso de inhibidores de la bomba de protones, uso de antibióticos)

\section{Prueba diagnóstica}

Prueba rápida de ureasa

\section{Histología con tinción de Giemsa}

(con o sin prueba rápida de ureasa asociada)

\section{Cultivo de H. pylori. con E test para estudio de sensibilidad/} resistencia antibiótica.

Antígeno en deposiciones $H$. pylori o Prueba de aire espirado con urea marcada

Reacción en cadena de polimerasa (PCR)

\section{Conclusiones}

La infección por $H$. pylori es un problema global de salud pública. Su presencia se ha asociado a múltiples patologías, incluyendo ulcera péptica, linfoma MALT gástrico y adenocarcinoma gástrico. Existe una variada disponibilidad de métodos para el diagnóstico de H. pylori y tratamientos para su erradicación. Las pruebas se deben elegir de acuerdo con la edad y factores de riesgo de CG de determinados pacientes. En términos generales, se recomiendan estudios no invasivos (antígeno en deposiciones y prueba de aire espirado) en poblaciones de bajo riesgo (menores de 40 años sin síntomas de alarma y sin factores de riesgo de $\mathrm{CG}$ ) y para control de erradicación de H. pylori. Si el paciente tiene síntomas de alarma, tiene antecedentes de CG familiar de primer grado o es mayor de 40 años, se prefiere el uso de métodos invasivos a través de la endoscopia digestiva alta con
PRU y/o tinción en biopsia gástrica. Si el paciente presenta una condición de subdiagnóstico de $H$. pylori, como el uso reciente de inhibidores de bomba de protones, uso reciente de antibióticos o fracaso de primera o segunda línea de tratamiento empírico, el cultivo o el uso de métodos moleculares que son más sensibles y específicos en la determinación de la presencia o ausencia de $H$. pylori, y además, pueden entregar información adicional, respecto a resistencia antibiótica lo que puede servir de guía para la indicación de un esquema de erradicación "a la medida" aumentando las chances de erradicación. Teniendo en cuenta la crecente resistencia antimicrobiana de $H$. pylori y la consecuente disminución en la efectividad de los esquemas convencionales de erradicación, no es posible establecer una recomendación universal de tratamiento. En general, este es un campo de investigación activo y aún con varias preguntas cruciales sin respuesta.

\section{Referencias}

1.- Correa P, Piazuelo MB. Evolutionary History of the Helicobacter pylori Genome: Implications for Gastric Carcinogenesis. Gut and liver. 2012; 6:21-8.

2.- Warren JR, Marshall B. Unidentified curved bacilli on gastric epithelium in active chronic gastritis. Lancet. 1983;1:1273-5.

3.- Soll AH. Consensus conference. Medical treatment of peptic ulcer disease. Practice guidelines. Practice Parameters Committee of the American College of Gastroenterology. JAMA.
1996;275:622-9.

4.- Schistosomes, liver flukes and Helicobacter pylori. IARC Working Group on the Evaluation of Carcinogenic Risks to Humans. Lyon, 7-14 June 1994. IARC Monogr Eval Carcinog Risks Hum. 1994;61:1-241. 
5.- Bouvard V, Baan R, Straif K, Grosse Y, Secretan B, El Ghissassi F, et al. A review of human carcinogens-Part B: biological agents. Lancet Oncol. 2009;10:321-2.

6.- Hooi JKY, Lai WY, Ng WK, Suen MMY, Underwood FE, Tanyingoh D, et al. Global Prevalence of Helicobacter pylori Infection: Systematic Review and Meta-Analysis. Gastroenterology. 2017;153:420-9.

7.- $\mathrm{Hu} \mathrm{Y}, \mathrm{Zhu} \mathrm{Y}, \mathrm{Lu}$ NH. Novel and Effective Therapeutic Regimens for Helicobacter pylori in an Era of Increasing Antibiotic Resistance. Front Cell Infect Microbiol. 2017;7:168.

8.- Parkin DM. The global health burden of infection-associated cancers in the year 2002. Int J Cancer. 2006;118:3030-44.

9.- Porras C, Nodora J, Sexton R, Ferreccio C, Jiménez S, Domínguez RL, et al. Epidemiology of Helicobacter pylori infection in six Latin American countries (SWOG Trial S0701). Cancer Causes Control. 2013;24:209-15.

10.- Figueroa G, Acuña R, Troncoso M, Portell DP, Toledo MS, Valenzuela J. Helicobacter pylori infection in Chile. Clin Infect Dis. 1997;25:983-9.

11.- Ortega JP, Espino A, Calvo B A, Verdugo P, Pruyas M, Nilsen E, et al. Infección por Helicobacter pylori en pacientes sintomáticos con patología gastroduodenal benigna: Análisis de 5.664 pacientes. Rev Med Chile 2010;138:529-35.

12.- Riquelme A. Gastroenterología y Hepatología Clínica clínica. Santiago: Editorial Mediterráneo; 2020.

13.- Ansari S, Yamaoka Y. Survival of Helicobacter pylori in gastric acidic territory. Helicobacter. 2017;22(4):10.1111/hel.12386.

14.- Malfertheiner P, Megraud $F$, O'Morain CA, Gisbert JP, Kuipers EJ, Axon AT, et al. Management of Helicobacter pylori infection-the Maastricht V/Florence Consensus Report. Gut. 2017;66:6-30.

15.- Mishra S. Is Helicobacter pylori good or bad? Eur J Clin Microbiol Infect Dis. 2013;32:301-4.

16.- McColl KE. Clinical practice. Helicobacter pylori infection. N Engl J Med. 2010;362:1597-604.

17.- Kusters JG, van Vliet AH, Kuipers EJ. Pathogenesis of Helicobacter pylori infection. Clin Microbiol Rev. 2006;19:449-90.

18.- McColl KE, Gillen D, El-Omar E. The role of gastrin in ulcer pathogenesis. Baillieres Best Pract Res Clin Gastroenterol. 2000;14:13-26.

19.- Graham DY. Helicobacter pylori update: gastric cancer, reliable therapy, and possible benefits. Gastroenterology. 2015;148:719-31.e3.

20.- Montalban C, Norman F. Treatment of gastric mucosa-associated lymphoid tissue lymphoma: Helicobacter pylori eradication and beyond. Expert Rev Anticancer Ther. 2006;6:361-71.

21.- Hudak L, Jaraisy A, Haj S, Muhsen K. An updated systematic review and meta-analysis on the association between Helicobacter pylori infection and iron deficiency anemia. Helicobacter. 2017;22.

22.- Frydman GH, Davis N, Beck PL, Fox JG. Helicobacter pylori Eradication in Patients with Immune Thrombocytopenic Purpura: A Review and the Role of Biogeography. Helicobacter. 2015;20:239-51.

23.- Campuzano-Maya G. Hematologic manifestations of Helicobacter pylori infection. World J Gastroenterol. 2014;20:12818-38.

24.- Gravina AG, Zagari RM, De Musis C, Romano L, Loguercio C, Romano M. Helicobacter pylori and extragastric diseases: A review. World J Gastroenterol. 2018;24:3204-21.

25.- Kayali S, Manfredi M, Gaiani F, Bianchi L, Bizzarri B, Leandro G, et al. Helicobacter pylori, transmission routes and recurrence of infection: state of the art. Acta bio-medica : Atenei Parmensis. 2018;89:72-6.

26.- Ko SW, Kim YJ, Chung WC, Lee SJ. Bismuth supplements as the firstline regimen for Helicobacter pylori eradication therapy: Systemic review and meta-analysis. Helicobacter. 2019;24:e12565.

27.- Patel SK, Pratap CB, Jain AK, Gulati AK, Nath G. Diagnosis of Helicobacter pylori: what should be the gold standard? World J Gastroenterol. 2014;20:1284759.

28.- Uotani T, Graham DY. Diagnosis of Helicobacter pylori using the rapid urease test. Ann Transl Med. 2015;3:9.
29.- Osaki T, Mabe K, Hanawa T, Kamiya S. Urease-positive bacteria in the stomach induce a false-positive reaction in a urea breath test for diagnosis of Helicobacter pylori infection. J Med Microbiol. 2008;57:814-9.

30.- Laine L, Lewin DN, Naritoku W, Cohen H. Prospective comparison of H\&E, Giemsa, and Genta stains for the diagnosis of Helicobacter pylori. Gastrointest Endosc. 1997;45:463-7.

31.- Lee JY, Kim N. Diagnosis of Helicobacter pylori by invasive test: histology. Ann Transl Med. 2015;3:10.

32.- Dixon MF, Genta RM, Yardley JH, Correa P. Classification and grading of gastritis. The updated Sydney System. International Workshop on the Histopathology of Gastritis, Houston 1994. Am J Surg Pathol. 1996;20:116181.

33.- Peixoto A, Silva M, Pereira P, Macedo G. Biopsies in Gastrointestinal Endoscopy: When and How. GE Port J Gastroenterol. 2016;23:19-27.

34.- Aydin O, Egilmez R, Karabacak T, Kanik A. Interobserver variation in histopathological assessment of Helicobacter pylori gastritis. World J Gastroenterol. 2003;9:2232-5.

35.- Chung WC, Jung SH, Oh JH, Kim TH, Cheung DY, Kim BW, et al. Dualpriming oligonucleotide-based multiplex PCR using tissue samples in rapid urease test in the detection of Helicobacter pylori infection. World J Gastroenterol. 2014;20:6547-53.

36.- Schabereiter-Gurtner C, Hirschl AM, Dragosics B, Hufnagl P, Puz S, Kovách $Z$, et al. Novel real-time PCR assay for detection of Helicobacter pylori infection and simultaneous clarithromycin susceptibility testing of stool and biopsy specimens. J Clin Microbiol. 2004:42:4512-8.

37.- Burucoa C, Delchier JC, CourillonMallet A, de Korwin JD, Mégraud F, Zerbib F, et al. Comparative evaluation of 29 commercial Helicobacter pylori serological kits. Helicobacter. 2013;18:169-79.

38.- Korkmaz H, Kesli R, Karabagli P, Terzi Y. Comparison of the diagnostic accuracy of five different stool antigen tests for the diagnosis of Helicobacter 


\section{Medicina Basada en la evidencia en Gastroenterología}

pylori infection. Helicobacter. 2013;18:384-91.

39.- Best LM, Takwoingi Y, Siddique $\mathrm{S}$, Selladurai A, Gandhi A, Low B, et al. Non-invasive diagnostic tests for Helicobacter pylori infection. Cochrane Database Syst Rev. 2018;3:CD012080.

40.- Perri F, Quitadamo M, Ricciardi R, Piepoli A, Cotugno R, Gentile A, et al. Comparison of a monoclonal antigen stool test (Hp StAR) with the 13C-urea breath test in monitoring Helicobacter pylori eradication therapy. World J Gastroenterol. 2005;11:5878-81.

41.- Atkinson NS, Braden B. Helicobacter pylori Infection: Diagnostic Strategies in Primary Diagnosis and After Therapy. Dig Dis Sci. 2016;61:19-24.

42.- Crowe SE. Helicobacter pylori Infection. N Engl J Med. 2019;380:1158-65.

43.- Abd Rahim MA, Johani FH, Shah SA, Hassan MR, Abdul Manaf MR. C-Urea Breath Test Accuracy for Helicobacter pylori Infection in the Asian Population: A Meta-Analysis. Ann Glob Health. 2019;85(1).

44.- Ferwana M, Abdulmajeed I, Alhajiahmed A, Madani W, Firwana B, Hasan R, et al. Accuracy of urea breath test in Helicobacter pylori infection: metaanalysis. World J Gastroenterol. 2015;21:1305-14.

45.- Calvet X, Sánchez-Delgado J, Montserrat A, Lario S, Ramírez-Lázaro MJ, Quesada $\mathrm{M}$, et al. Accuracy of diagnostic tests for Helicobacter pylori: a reappraisal. Clin Infect Dis. 2009;48:1385-91.

46.- Al-Humayed SM, Ahmed ME, Bello CS, Tayyar MA. Comparison of 4 laboratory methods for detection of Helicobacter pylori. Saudi Med J. 2008;29:530-2.

47.- Redéen S, Petersson F, Törnkrantz E, Levander H, Mårdh E, Borch K. Reliability of Diagnostic Tests for Helicobacter pylori Infection. Gastroenterol Res Pract. 2011;2011:940650.

48.- Destura RV, Labio ED, Barrett LJ, Alcantara CS, Gloria VI, Daez ML, et al. Laboratory diagnosis and susceptibility profile of Helicobacter pylori infection in the Philippines. Ann Clin Microbiol Antimicrob. 2004;3:25.

49.- Katz PO, Gerson LB, Vela MF. Guidelines for the diagnosis and management of gastroesophageal reflux disease. Am J Gastroenterol. 2013;108:308-28; quiz 29.

50.- Beresniak A, Malfertheiner P, Franceschi F, Liebaert F, Salhi H, Gisbert JP. Helicobacter pylori "Test-and-Treat" strategy with urea breath test: A costeffective strategy for the management of dyspepsia and the prevention of ulcer and gastric cancer in Spain-Results of the Hp-Breath initiative. Helicobacter. 2020:e12693.

51.- Choi IJ, Kim CG, Lee JY, Kim YI, Kook MC, Park B, et al. Family History of Gastric Cancer and Helicobacter pylori Treatment. N Engl J Med. 2020;382:42736.

52.- Wong BC, Lam SK, Wong WM, Chen JS, Zheng TT, Feng RE, et al. Helicobacter pylori eradication to prevent gastric cancer in a high-risk region of China: a randomized controlled trial. JAMA. 2004;291:187-94.

53.- Coppelli L, Díaz LA, Riquelme A, Waeger C, Rollán A, Bellolio E, et al. [Protocolized referral to endoscopy and Helicobacter pylori detected in stools aimed to decrease endoscopy waiting lists]. Rev Med Chile 2019;147:1382-9. 